\title{
Decadal GPS-derived ice surface velocity along the transect from Zhongshan Station to and around Dome Argus, East Antarctica, 2005-16
}

\author{
Yang YUANDE, ${ }^{1}$ Ke HAO, ${ }^{1}$ Wang ZEMIN,${ }^{1}$ Li FEI, ${ }^{1}$ Ding MINGHU, ${ }^{2}$ Sun $\mathrm{BO},{ }^{3}$ Jin $\mathrm{BO},{ }^{4}$ \\ Wang LIANZHONG, ${ }^{5}$ Ai SONGTAO ${ }^{1}$ \\ ${ }^{1}$ Chinese Antarctic Center of Surveying and Mapping, Wuhan University, 129 Luoyu Road, Wuhan 430079, China. \\ E-mail: kehao1984@whu.edu.cn \\ ${ }^{2}$ Institute of Climate System, Chinese Academy of Meteorological Sciences, Beijing 100081, China \\ ${ }^{3}$ Polar research institute of China, Shanghai 200136, China \\ ${ }^{4}$ Chinese Arctic and Antarctic Administration, Beijing 100860, China \\ ${ }^{5}$ Heilongjiang Bureau of Surveying and Mapping, Haerbin 150081, China
}

\begin{abstract}
Using repeat GPS measurements during 2005-16, we calculated and updated two-dimensional high-resolution decadal ice surface velocity estimates along the traverse route from Zhongshan Station to and around Dome Argus, East Antarctica. Along the 71 sites of the transect, the magnitudes of ice velocity increased from near 0 in Dome Argus to 1,10 and $\sim 100 \mathrm{~m} \mathrm{a}^{-1}$ at the sites DT416, DT333 and LT980, respectively. The comparison between GPS and interferometric synthetic aperture radar (InSAR) derived results agree well when the magnitude of the ice surface velocities is faster than $5 \mathrm{~m} \mathrm{a}^{-1}$, and disagree for slower flow velocities. A scale value 1.15 and 0.12 can be applied to InSAR derived results over this region with ice surface velocity larger and $<5 \mathrm{~m} \mathrm{a}^{-1}$, respectively. We attributed the cause of the discrepancy to the insensitivity of InSAR to the magnitude of low ice surface velocities, thus confirming the importance of GPS fieldwork-based ground truth high-resolution ice velocity estimates to constrain ice-sheet dynamics.
\end{abstract}

KEYWORDS: Antarctic glaciology, ice velocity, remote sensing

\section{INTRODUCTION}

Ice sheets play a major role in global climate change and sealevel rise. The mass balance of the Antarctic ice sheet is an important climatic variable since it has an important impact on global sea-level rise (Meier, 1993; Alley and others, 2005), based on the fact that it is the largest freshwater ice reservoir on Earth. Mass balance and other glaciological studies require knowledge of ice velocity, surface elevation, ice thickness and snow accumulation, either from direct field measurements or via remote-sensing methods (Paterson, 1994; Rignot and others, 2011). Considering the difficulties of accessibility, the hostile environment and the logistic problems in Antarctica, the use of the GPS receivers has become a standard tool for field measurement of ice kinematics and surface topography in Antarctica (Tabacco and others, 1998; Capra and others, 2000; Gudmundsson, 2006; King and others, 2007; Zhang and others, 2007; Cheng and others, 2009; Yang and others, 2014).

Since the first Chinese National Antarctic Research Expeditions (CHINARE) along the traverse route from Zhongshan station to Dome Argus (Dome A) in 1996 (shown in Fig. 1a and Table 2), the studies of mass balance, ice temperature, meteorological measurements, glacio-chemical of surface snow and shallow ice cores, and stratigraphy in snow pits and snow/firn cores have been carried out (Qin and others, 2004; Ren and others, 2004; Xiao and others, 2008; Zhang and others, 2008). Since the 21 st CHINARE in 2005, meteorological measurements from automatic weather stations, ice-sheet thickness and bed topography, surface mass balance (SMB)/snow accumulation, surface topography and velocity field have been studied (Hou and others, 2007; Zhang and others, 2007; Xiao and others, 2008; Cheng and others, 2009; Sun and others, 2009; Cui and others, 2010; Ma and others, 2010; Bell and others, 2011; Ding and others, 2011, 2016; Yang and others, 2014).

Along the traverse route (shown in Fig. 1a and from LGB72 to KL in Table 2), GPS poles were established at $\sim 2 \mathrm{~km}$ intervals. From 1997/98 to 2004/05, GPS measurements were carried out at 42 poles, with 19 GPS sites reoccupied for more than 2 times along the traverse route. With these repeat GPS measurements, horizontal surface ice velocities were calculated and listed in Table 2 (Zhang and others, 2008). Since 2005, 60 poles around Dome A were set up to estimate SMB and map the ice surface topography in a $30 \times 30 \mathrm{~km}$ area centered at Kunlun station. Among the 60 poles, 12 poles were measured with repeat GPS in 2008, and GPS data were collected at 47 poles in 2013. With these 12 repeat GPS measurements, the surface velocities around Dome A were derived and listed in Table 2 (Yang and others, 2014).

The key objective of this paper is to update the new result of the GPS data collected in the CHINARE after 2005. With these repeat GPS measurements, the horizontal surface ice velocities are computed. Combined with the early results, we present the horizontal surface ice velocities at a higher resolution along the transect and around Dome A (the other sites in Table 2), East Antarctica. The GPS results are then compared with the interferometric synthetic aperture radar (InSAR) results reported by Mouginot and others (2017). 
a

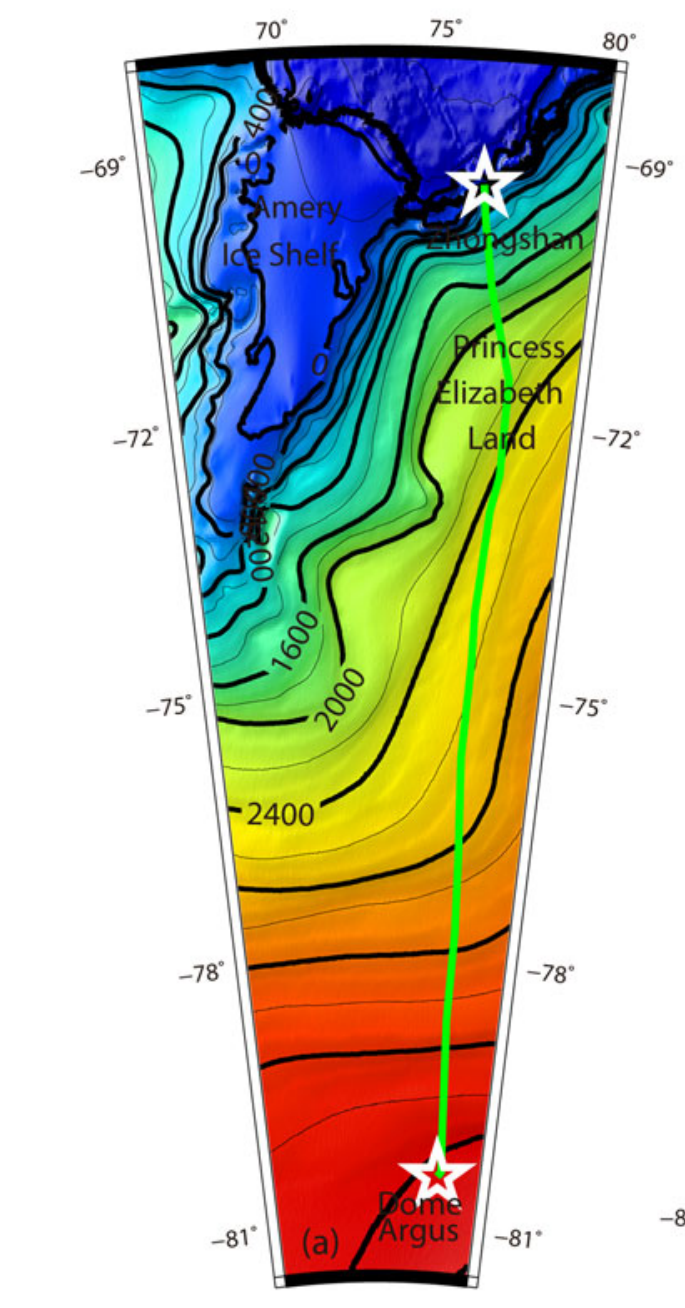

$-1000-500 \quad 0 \quad 50010001500200025003000350040004500$ topo $(\mathrm{m})$

C b

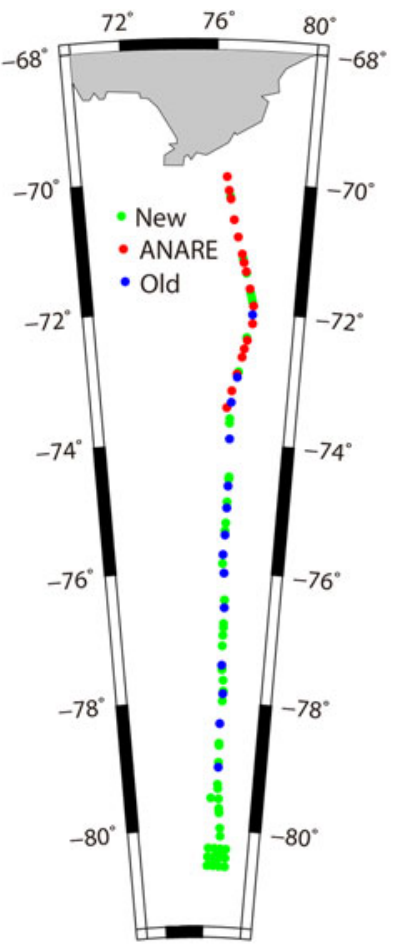

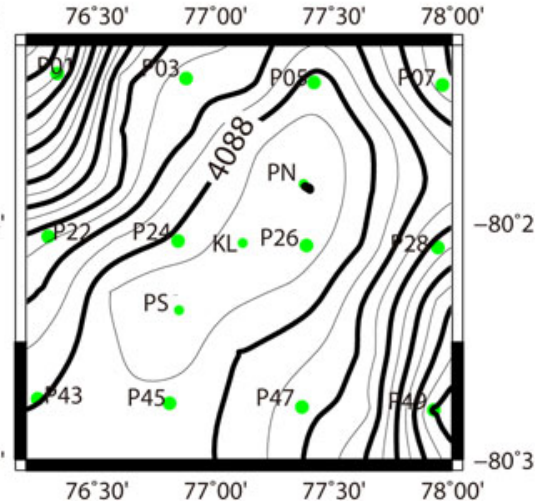

Fig. 1. (a) Sketch map showing the locations of along the transect, and (b) poles for GPS measurements along the transect, and (c) poles for GPS measurements around Dome A.

\section{FIELD GPS SURVEY AND DATA PROCESSING}

Along the traverse route, GPS poles were established at $\sim 2 \mathrm{~km}$ intervals in 2007. Poles are random selected when the vehicle stopped (Zhang and others, 2008; Cheng and others, 2009), and GPS measurements carried out in different years. GPS measurements varied in different years along the transect from Zhongshan Station to and around Dome A. Before 2005, GPS measurements in different years were described in Zhang and others (2008). In 2005/06, GPS surveys at 26 and 19 poles were measured along the transect from Zhongshan Station to and around Dome A, respectively. Three dual-frequency GPS receivers were used to collect GPS data at an interval of $15 \mathrm{~s}$ in all the GPS surveys. Along the same transect, GPS surveys at 5, 20, 10, 19 and 45 poles were measured in 2007/08, 2008/09, 2009/10, 2010/11 and 2015/16, respectively. Moreover, GPS surveys of 9, 19, 47 and 53 poles were measured around Dome A in 2008, 2010, 2011 and 2016, respectively. Two dual-frequency GPS receivers were used to collect GPS data. As we just focus on the ice velocities along the same transect and around Dome A, we only use the repeat GPS data here. Among these measurements, 52 repeat poles were measured lasting more than $1 \mathrm{~h}$ along the transect and 50 repeats measured lasting more than 25 min over Dome A (Fig. 1 and Table 2), respectively. In this paper, we only focus on the new results of 15 poles (Fig. 1), with 12 poles of Yang and others (2014) and three new lasting more than $1 \mathrm{~h}$ (Kunlun station (KL), south peak (PS) and north peak (PN)).

For the 52 repeat poles along the transect and three poles (PN, PS and $\mathrm{KL}$ ) around the Dome A, the GPS measurements were processed using the GAMIT/GLOBK software suite, Version 10.50 (King, 2002), developed at MIT. Seven International GNSS Service (IGS) stations around Antarctica, including MAW1, CAS1, DAV1, DUM1, MCM4, OHI2 and SYOG, were used in the processing. During the data processing, the following options were selected: (1) International GNSS Service (IGS) SP3 precise ephemerides were used; (2) the IGS stations were tightly constrained (within $1 \mathrm{~cm}$ ) to their ITRF 2008 values, while the six reference stations at Dome A were loosely constrained (within $100 \mathrm{~m}$ ); (3) an elevation 
Table 1. Horizontal velocities at GPS sites (unit: degrees, minutes, seconds) before and after 2005

\begin{tabular}{|c|c|c|c|c|c|c|c|c|}
\hline Site & Lon.E & Lat.S & Heightm & Dis.km & Velo. $\mathrm{m} \mathrm{a}^{-1}$ & Azimuth $^{\circ}$ & Velo*. $\mathrm{m} \mathrm{a}^{-1}$ & Azimuth*o \\
\hline DT008 & 775515.9 & 720047.9 & 2373.71 & 310 & 24.5 & 296 & $24.4 \pm 0.1$ & $299.9 \pm 0.1$ \\
\hline DT063 & 771718.0 & 725850.5 & 2545.17 & 420 & 9 & 310 & $8.1 \pm 0.2$ & $300.3 \pm 1.0$ \\
\hline DT085 & 770041.5 & 732205.5 & 2560.73 & 464 & 9.4 & 268 & $9.5 \pm 0.1$ & $264.3 \pm 0.2$ \\
\hline DT118 & 765918.0 & 735605.6 & 2644.15 & 528 & 17.7 & 277 & $17.6 \pm 0.4$ & $276.1 \pm 0.6$ \\
\hline DT158 & 770019.5 & 743934.2 & 2739.75 & 608 & 10.7 & 291 & $10.4 \pm 0.1$ & $290.7 \pm 0.3$ \\
\hline DT177 & 765803.1 & 745942.5 & 2787.17 & 647 & 10.4 & 275 & $10.7 \pm 0.1$ & $276 \pm 0.3$ \\
\hline DT217 & 765011.3 & 754304.6 & 2813.69 & 728 & 12.8 & 270 & $12.3 \pm 0.1$ & $272.2 \pm 0.2$ \\
\hline DT233 & 765618.3 & 760020.2 & 2792.99 & 760 & 15.8 & 277 & $16.1 \pm 0.2$ & $277.3 \pm 0.3$ \\
\hline DT263 & 770127.9 & 763227.6 & 2823.80 & 820 & 17.1 & 316 & $17.3 \pm 0.1$ & $316.5 \pm 0.1$ \\
\hline DT313 & 765945.3 & 772542.5 & 3023.16 & 920 & 18.5 & 325 & $18.3 \pm 0.1$ & $325.2 \pm 0.2$ \\
\hline DT338 & 770820.9 & 775216.3 & 3154.93 & 970 & 7.6 & 316 & $7.6 \pm 0.2$ & $316.4 \pm 0.8$ \\
\hline DT364 & 770003.6 & 782014.7 & 3373.28 & 1022 & 3.0 & 36 & $3.0 \pm 0.1$ & $35.3 \pm 0.6$ \\
\hline DT401 & 765956.1 & 790047.6 & 3734.90 & 1098 & 1.3 & 9 & $1.3 \pm 0.1$ & $8.0 \pm 2.3$ \\
\hline P03 & 765234.1 & 801641.2 & 4083.01 & / & $0.11 \pm 0.02$ & $299 \pm 4.1$ & $0.11 \pm 0.01$ & $309.3 \pm 3.1$ \\
\hline P05 & 772458.5 & 801653.5 & 4089.24 & / & $0.04 \pm 0.02$ & $29.5 \pm 15.2$ & $0.04 \pm 0.01$ & $23.5 \pm 7.9$ \\
\hline P07 & 775727.2 & 801701.6 & 4076.88 & / & $0.10 \pm 0.02$ & $67.3 \pm 4.1$ & $0.11 \pm 0.02$ & $63.3 \pm 4.6$ \\
\hline P22 & 761738.7 & 802441.2 & 4081.61 & / & $0.18 \pm 0.03$ & $306.7 \pm 5.2$ & $0.16 \pm 0.01$ & $305.4 \pm 1.1$ \\
\hline P24 & 765030.3 & 802454.6 & 4088.37 & / & $0.06 \pm 0.02$ & $318.5 \pm 10.2$ & $0.05 \pm 0.01$ & $313.9 \pm 1.7$ \\
\hline P26 & 772302.0 & 802508.7 & 4090.87 & / & $0.03 \pm 0.03$ & $130.1 \pm 24.2$ & $0.03 \pm 0.01$ & $119.4 \pm 3.7$ \\
\hline P28 & 775621.6 & 802515.2 & 4078.93 & / & $0.10 \pm 0.02$ & $113.8 \pm 4.2$ & $0.10 \pm 0.01$ & $113.3 \pm 1.4$ \\
\hline P43 & 761458.6 & 803254.5 & 4087.84 & / & $0.06 \pm 0.05$ & $315.3 \pm 21.7$ & $0.04 \pm 0.01$ & $287.7 \pm 9.5$ \\
\hline P45 & 764827.5 & 803308.1 & 4089.15 & / & $0.06 \pm 0.04$ & $161 \pm 15.8$ & $0.05 \pm 0.01$ & $152 \pm 6.3$ \\
\hline P47 & 772152.0 & 803319.4 & 4084.66 & / & $0.10 \pm 0.02$ & $134.6 \pm 6.6$ & $0.10 \pm 0.01$ & $126.2 \pm 4.1$ \\
\hline P49 & 775516.8 & 803328.6 & 4067.68 & / & $0.18 \pm 0.02$ & $113.3 \pm 3.9$ & $0.18 \pm 0.01$ & $110.9 \pm 1.9$ \\
\hline
\end{tabular}

* After 2005.

cut-off angle of $15^{\circ}$ was adopted; (4) antenna-phase center variation corrections were applied; (5) the ionospheric-free linear combination of the L1 and L2 frequencies was used; (6) corrections due the solid-Earth and pole tides were applied; (7) the dry component of the zenith tropospheric delay was implemented using the Saastamoinen model with global mapping function; and (8) the wet component of the zenith tropospheric delay was estimated every $2 \mathrm{~h}$ using the mapping function. The GAMIT solutions were then combined using the GLOBK software.

Two steps were used for 12 poles of Yang and others (2014) over Dome A, and the details shown in Yang and others (2014). GPS measurements in the reference station were first processed using the GAMIT/GLOBK software. Then Version 2.50 Trimble Business Center (TBC) was used to obtain the baseline between a roving station and a reference station. During the data processing, IGS SP3 precise ephemerides were used and an elevation cut-off angle of $15^{\circ}$ was adopted.

To account for the effect of tectonic motion, we corrected for the east-west component and north-south component of velocities at MAW1, CAS1, DAV1, DUM1, MCM4, OHI2 and SYOG using the result of Jiang and others (2009). To reduce the impact of plate motion, we fix the coordinates of seven IGS stations to the same epoch 2016.0 when the data were processed with GAMIT.

\section{RESULTS AND DISCUSSION}

\section{Surface velocity comparison before and after 2005}

Horizontal surface velocities at 19 GPS sites along the traverse route were calculated by Zhang and others (2008) from $1997 / 98$ to $2004 / 05$. Since 2005, 52 poles along the transect repeat measured (Table 2). There were 14 overlap poles shown in Figure 1 before and after 2005, and the results shown in Table 1 . The largest velocity speed difference located at site DT063 was $0.9 \mathrm{~m} \mathrm{a}^{-1}$, where the difference was $\sim 10 \%$ of the velocity speed $9 \mathrm{~m} \mathrm{a}^{-1}$. The mean difference and the Std dev. along the traverse route were $0.1 \mathrm{~m} \mathrm{a}^{-1}$ and $0.3 \mathrm{~m} \mathrm{a}^{-1}$, respectively. Moreover, the largest directional difference of $9.7^{\circ}$ is noted at site DT063, with the mean difference and Std dev. at $0.5^{\circ}$ and $3.1^{\circ}$, respectively. The large difference may indicate the terrain change in the location. Compared with the mean surface velocity speed of $12.0 \mathrm{~m} \mathrm{a}^{-1}$ along the traverse route, the small mean difference value of $0.1 \mathrm{~m} \mathrm{a}^{-1}$ indicates that the velocity estimate is robust.

Around the Dome A, new horizontal surface results in 12 poles were calculated from 2008 and 2016 GPS data. The largest difference before and after 2013 appeared in P43, with the speed difference $2.3 \mathrm{~cm} \mathrm{a}^{-1}$ and directional difference $27.6^{\circ}$, respectively. Compared with the results along the traverse route, the larger directional difference indicates that the smaller accuracy in coordinates leads to the relative larger error in Dome A. This is consistent with the larger uncertainty at P43 in Table 2 (Yang and others, 2014). The mean difference and the Std dev. around the Dome A are 0.6 and $1.0 \mathrm{~cm} \mathrm{a}^{-1}$, respectively, while the corresponding directional difference and the Std dev. are at $5.6^{\circ}$ and $8.8^{\circ}$, respectively. Moreover, the mean velocity and the mean difference are at 12.0 and $0.1 \mathrm{~m} \mathrm{a}^{-1}$ along the traverse route, compared with the same estimated values of 11.0 and $1.0 \mathrm{~cm} \mathrm{a}^{-1}$ around Dome A, respectively. Therefore, we concluded that higher accuracy and/or spatially dense sampled GPS measurements are required around Dome $A$ to account for the high spatial velocity variabilities. 
Table 2. Horizontal velocities at GPS sites (unit: degrees, minutes, seconds) along the traverse route and around the Dome Argus

\begin{tabular}{|c|c|c|c|c|c|c|}
\hline Site & Lon.E & Lat.S & Heightm & Dis. km & Velo.m a ${ }^{-1}$ & Azim. ${ }^{\circ}$ \\
\hline LGB72* & 762936 & 695515 & 1056 & 68 & 52.9 & 306 \\
\hline LT980 & 763531 & 700749 & 1291 & 92 & 98.2 & 306 \\
\hline LT975 & 76397.7 & 701310.8 & 1372.87 & 102 & $84.2 \pm 0.1$ & $315.2 \pm 0.1$ \\
\hline LGB71* & 764059 & 701532 & 1406 & 106 & 62.6 & 318 \\
\hline LGB70* & 765159 & 703433 & 1669 & 142 & 25.5 & 331 \\
\hline LT940 & 770437 & 705007 & 1870 & 172 & 17.5 & 324 \\
\hline LGB69* & 770440 & 705007 & 1871 & 173 & 17.7 & 323 \\
\hline LGB68* & 771719 & 710543 & 2013 & 202 & 14.1 & 310 \\
\hline LT921 & 772056.7 & 710956.0 & 2080.59 & 211 & $14.1 \pm 0.1$ & $302.6 \pm 0.2$ \\
\hline LT918 & 772342 & 711318 & 2095 & 217 & 13.7 & 300 \\
\hline LGB67* & 773040 & 712138 & 2152 & 232 & 14.8 & 287 \\
\hline LT909 & 773156.1 & 712255.4 & 2155.44 & 235 & $12.5 \pm 0.2$ & $296.7 \pm 0.5$ \\
\hline LGB66* & 774350 & 713714 & 2230 & 262 & 22.6 & 292 \\
\hline LT891 & 774654.0 & 714116.5 & 2255.70 & 271 & $23 \pm 0.1$ & $296.3 \pm 0.1$ \\
\hline LT887 & 775046.0 & 714534.4 & 2288.29 & 280 & $24.1 \pm 0.1$ & $294.5 \pm 0.1$ \\
\hline LT883 & 775318.8 & 714853.0 & 2298.41 & 288 & $23 \pm 0.5$ & $304.2 \pm 0.6$ \\
\hline LGB65* & 775703 & 715251 & 2341 & 292 & 22.5 & 295 \\
\hline DT008 $^{+}$ & 775515.9 & 720047.9 & 2373.71 & 310 & $24.4 \pm 0.1$ & $299.9 \pm 0.1$ \\
\hline LGB64* & 775658 & 720902 & 2367 & 324 & 24.2 & 297 \\
\hline DT028 & 774133.0 & 722200.5 & 2415.32 & 350 & $22.0 \pm 0.2$ & $303 \pm 0.2$ \\
\hline LGB63* & 774323 & 722438 & 2439 & 354 & 21 & 304 \\
\hline DT038 & 773506 & 723230 & 2433 & 370 & 21.6 & 306 \\
\hline LGB62* & 772937 & 724016 & 2483 & 384 & 21.3 & 306 \\
\hline DT058 & 772041.3 & 725338.7 & 2533.21 & 410 & $11.1 \pm 0.1$ & $304.3 \pm 0.4$ \\
\hline LGB61* & 771547 & 725552 & 2525 & 412 & 8.6 & 310 \\
\hline DT063 $^{+}$ & 771718.0 & 725850.5 & 2545.17 & 420 & $8.1 \pm 0.2$ & $300.3 \pm 1.0$ \\
\hline LGB60* & 770137 & 731129 & 2595 & 442 & 7.6 & 265 \\
\hline DT085 ${ }^{+}$ & 770041.5 & 732205.5 & 2560.73 & 464 & $9.5 \pm 0.1$ & $264.3 \pm 0.2$ \\
\hline LGB59* & 764716 & 732707 & 2549 & 475 & 10.6 & 276 \\
\hline DT100 & 765745.7 & 733714.1 & 2609.69 & 493 & $13.4 \pm 0.3$ & $286.9 \pm 0.6$ \\
\hline DT104 & 765746.6 & 734122.6 & 2613.00 & 501 & $14.4 \pm 0.1$ & $283.9 \pm 0.2$ \\
\hline DT118 $8^{+}$ & 765918.0 & 735605.6 & 2644.15 & 528 & $17.6 \pm 0.4$ & $276.1 \pm 0.6$ \\
\hline DT132 & 770036 & 741041 & 2675 & 556 & 18.2 & 283 \\
\hline DT150 & 770219.8 & 743052.3 & 2720.36 & 592 & $15.8 \pm 0.1$ & $283.9 \pm 0.2$ \\
\hline DT151 & 770159.3 & 743123.6 & 2718.50 & 594 & $15.4 \pm 0.2$ & $284.4 \pm 0.4$ \\
\hline DT152 & 770124.5 & 743244.1 & 2717.00 & 596 & $14.4 \pm 0.2$ & $286.3 \pm 0.5$ \\
\hline DT158 ${ }^{\dagger}$ & 770019.5 & 743934.2 & 2739.75 & 608 & $10.4 \pm 0.1$ & $290.7 \pm 0.3$ \\
\hline DT171 & 765837.7 & 745406.8 & 2777.43 & 636 & $8.9 \pm 0.4$ & $282.6 \pm 1.2$ \\
\hline DT177 ${ }^{+}$ & 765803.1 & 745942.5 & 2787.17 & 647 & $10.7 \pm 0.1$ & $276 \pm 0.3$ \\
\hline DT189 & 765627.4 & 751342.0 & 2783.96 & 670 & $10.9 \pm 0.3$ & $283.6 \pm 0.7$ \\
\hline DT193 & 765504.9 & 752103.1 & 2802.86 & 679 & $10.1 \pm 0.5$ & $280.1 \pm 1.4$ \\
\hline DT200 ${ }^{+}$ & 765500.3 & 752458.1 & 2807.32 & 693 & $10.2 \pm 0.5$ & $278.3 \pm 1.4$ \\
\hline DT217 $7^{+}$ & 765011.3 & 754304.6 & 2813.69 & 728 & $12.3 \pm 0.1$ & $272.2 \pm 0.2$ \\
\hline DT224 & 764938.9 & 755132.5 & 2787.62 & 743 & $14.3 \pm 0.4$ & $274.3 \pm 0.7$ \\
\hline DT $233^{+}$ & 765618.3 & 760020.2 & 2792.99 & 760 & $16.1 \pm 0.2$ & $277.3 \pm 0.3$ \\
\hline DT256 & 770146.5 & 762504.2 & 2839.50 & 806 & $13.4 \pm 0.1$ & $297.8 \pm 0.2$ \\
\hline DT263 ${ }^{+}$ & 770127.9 & 763227.6 & 2823.80 & 820 & $17.3 \pm 0.1$ & $316.5 \pm 0.1$ \\
\hline DT276 & 770121.9 & 764702.9 & 2884.14 & 846 & $19.3 \pm 0.2$ & $311.5 \pm 0.2$ \\
\hline DT280 & 770131.1 & 765047.0 & 2886.77 & 854 & $19.9 \pm 0.5$ & $330.5 \pm 0.5$ \\
\hline DT287 & 765949.3 & 765803.7 & 2910.92 & 868 & $18.6 \pm 0.5$ & $323.5 \pm 0.5$ \\
\hline DT296 & 765844.1 & 770745.7 & 2942.71 & 886 & $21.0 \pm 0.5$ & $332.5 \pm 0.5$ \\
\hline DT313 ${ }^{+}$ & 772542.5 & 765945.3 & 3023.16 & 920 & $18.3 \pm 0.1$ & $325.2 \pm 0.2$ \\
\hline DT317 & 770158.4 & 773002.3 & 3020.12 & 928 & $17.1 \pm 0.5$ & $325.7 \pm 0.8$ \\
\hline DT326 & 770709.9 & 773944.1 & 3070.83 & 946 & $13.3 \pm 0.2$ & $324.3 \pm 0.5$ \\
\hline DT336 & 771103.0 & 774940.2 & 3153.59 & 966 & $8.1 \pm 0.2$ & $317.8 \pm 0.8$ \\
\hline DT338 ${ }^{+}$ & 770820.9 & 775216.3 & 3154.93 & 970 & $7.6 \pm 0.2$ & $316.4 \pm 0.8$ \\
\hline DT344 & 770723.5 & 775905.1 & 3168.18 & 982 & $5.5 \pm 0.1$ & $329.1 \pm 0.5$ \\
\hline DT364 ${ }^{+}$ & 782014.7 & 770003.6 & 3373.28 & 1022 & $3.0 \pm 0.1$ & $35.3 \pm 0.6$ \\
\hline DT381 & 765959.7 & 783830.3 & 3517.40 & 1057 & $2.5 \pm 0.1$ & $14.3 \pm 0.6$ \\
\hline DT383 & 770009.9 & 784034.1 & 3532.35 & 1061 & $2.4 \pm 0.2$ & $16.3 \pm 2.4$ \\
\hline DT397 & 770023.0 & 785616.4 & 3692.02 & 1089 & $1.8 \pm 0.1$ & $15.1 \pm 2.4$ \\
\hline DT40 $1^{\dagger}$ & 765956.1 & 790047.6 & 3734.90 & 1098 & $1.3 \pm 0.1$ & $8.0 \pm 2.3$ \\
\hline DT416 & 765942.8 & 791646.7 & 3841.59 & 1128 & $1.0 \pm 0.1$ & $354.4 \pm 3.0$ \\
\hline DT419 & 770152.4 & 792045.9 & 3855.70 & 1135 & $0.8 \pm 0.1$ & $336.5 \pm 2.6$ \\
\hline DT428 & 762734.3 & 792934.2 & 3887.92 & 1152 & $0.9 \pm 0.2$ & $330 \pm 4.8$ \\
\hline DT429 & 770737.4 & 793022.4 & 3909.43 & 1154 & $0.7 \pm 0.1$ & $323.7 \pm 2.6$ \\
\hline DT437 & 771042.4 & 793911.1 & 3957.52 & 1170 & $0.7 \pm 0.3$ & $332.7 \pm 11.6$ \\
\hline DT438 & 771107.8 & 794027.1 & 3963.04 & 1172 & $0.7 \pm 0.2$ & $330.4 \pm 10.8$ \\
\hline DT441 & 771253.2 & 794326.4 & 3977.46 & 1178 & $0.5 \pm 0.1$ & $329.1 \pm 5.6$ \\
\hline
\end{tabular}


Table 2. (Cont.)

\begin{tabular}{|c|c|c|c|c|c|c|}
\hline Site & Lon.E & Lat.S & Heightm & Dis. km & Velo.m $\mathrm{a}^{-1}$ & Azim. ${ }^{\circ}$ \\
\hline DT454 & 772016.7 & 795743.9 & 4015.94 & 1204 & $0.3 \pm 0.1$ & $330.5 \pm 14.4$ \\
\hline DT461 & 772325.3 & 800512.7 & 4043.41 & 1219 & $0.1 \pm 0.1$ & $338.4 \pm 20.1$ \\
\hline $\mathrm{PN}$ & 772222.9 & 802201.6 & 4092.11 & 1241 & $0.02 \pm 0.01$ & $190.9 \pm 7.6$ \\
\hline $\mathrm{KL}$ & 770658.3 & 802501.0 & 4092.16 & 1250 & $0.03 \pm 0.01$ & $260.6 \pm 2.0$ \\
\hline $\mathrm{P}_{0}{ }^{+}$ & 762001.0 & 801626.0 & 4061.11 & I & $0.29 \pm 0.02$ & $298.4 \pm 1.6$ \\
\hline $\mathrm{PO}^{+}$ & 765234.1 & 801641.2 & 4083.01 & I & $0.11 \pm 0.01$ & $309.3 \pm 3.1$ \\
\hline $\mathrm{P}^{\circ} 5^{+}$ & 772458.5 & 801653.5 & 4089.24 & l & $0.04 \pm 0.01$ & $23.5 \pm 7.9$ \\
\hline $\mathrm{P}^{\circ} 7^{+}$ & 775727.2 & 801701.6 & 4076.88 & I & $0.11 \pm 0.02$ & $63.3 \pm 4.6$ \\
\hline $\mathrm{P} 22^{+}$ & 761738.7 & 802441.2 & 4081.61 & I & $0.16 \pm 0.01$ & $305.4 \pm 1.1$ \\
\hline $\mathrm{P} 24^{+}$ & 765030.3 & 802454.6 & 4088.37 & l & $0.05 \pm 0.01$ & $313.9 \pm 1.7$ \\
\hline $\mathrm{P} 26^{+}$ & 772302.0 & 802508.7 & 4090.87 & I & $0.03 \pm 0.01$ & $119.4 \pm 3.7$ \\
\hline $\mathrm{P} 28^{+}$ & 775621.6 & 802515.2 & 4078.93 & I & $0.10 \pm 0.01$ & $113.3 \pm 1.4$ \\
\hline $\mathrm{P} 43^{+}$ & 761458.6 & 803254.5 & 4087.84 & I & $0.04 \pm 0.01$ & $287.7 \pm 9.5$ \\
\hline $\mathrm{P} 45^{+}$ & 764827.5 & 803308.1 & 4089.15 & l & $0.05 \pm 0.01$ & $152 \pm 6.3$ \\
\hline $\mathrm{P} 47^{+}$ & 772152.0 & 803319.4 & 4084.66 & I & $0.10 \pm 0.01$ & $126.2 \pm 4.1$ \\
\hline $\mathrm{P} 49^{+}$ & 775516.8 & 803328.6 & 4067.68 & l & $0.18 \pm 0.01$ & $110.9 \pm 1.9$ \\
\hline PS & 765047.9 & 802825.9 & 4092.04 & I & $0.02 \pm 0.01$ & $77.7 \pm 8.6$ \\
\hline
\end{tabular}

* Measured by ANARE.

+ Repeat measured.

\section{Surface velocity field along the transect and around Dome A}

Using the repeated GPS results of 52 poles along the route and 15 poles over Dome A since 2005, the surface icevelocities along the traverse route and around Dome $A$ were derived. We also collect the surface ice-velocity at other sites during the traverse shown in Figure 1, including four sites in Zhang and others (2008) and 15 sites in Kiernan (2001). Besides the results from 12 poles in Yang and others (2014), the velocity fields from KL, PS and PN around Dome A were also derived. Table 2 summarizes the velocity results.

The mean velocity speed over Dome $\mathrm{A}$ is $\sim 8.8 \mathrm{~cm} \mathrm{a}^{-1}$, with the maximum velocity speed reaching $\sim 28.7 \mathrm{~cm} \mathrm{a}^{-1}$ at P01 in the northwest corner around Dome A. The minimum surface velocity speed located at PS and PN, which was $\sim 1.7$ and $1.9 \mathrm{~cm} \mathrm{a}^{-1}$, respectively. The measured velocity speed at $\mathrm{KL}$ was $\sim 2.9 \mathrm{~cm} \mathrm{a}^{-1}$. The velocity speed over Dome A, which is near the summit of East Antarctica Ice Sheet, is larger than the velocity speed over Dome $\mathrm{C}$ because the latter has many gentle slopes than at the summit (Vittuari and others, 2004), 2.8\% versus $12.0 \%$.

The 2D surface ice-velocity vectors map is shown in Figure 2 . The flow directions at these sites are roughly consistent with the downslope motion of the ice sheet. The horizontal surface velocity values increase with distance from the summit. From Dome A to DT416 (150 km from the summit of Dome $\mathrm{A}$ ), the velocity increases to $1.0 \mathrm{~m} \mathrm{a}^{-1}$, with the increasing rate $\sim 0.3 \mathrm{~m} \mathrm{a}^{-1} 50 \mathrm{~km}^{-1}$. Moreover, the velocity increases to $10 \mathrm{~m} \mathrm{a}^{-1}$ at site DT333 $(300 \mathrm{~km}$ from the summit of Dome A), with the increasing rate $3 \mathrm{~m} \mathrm{a}^{-1} 50 \mathrm{~km}^{-1}$, and this indicates a much steeper terrain for such region. Furthermore, the velocity increases to larger than $18 \mathrm{~m} \mathrm{a}^{-1}$ at site DT313 and extends $\sim 100 \mathrm{~km}$ distance to site DT263. Then, the slower velocity is $<18 \mathrm{~m} \mathrm{a}^{-1}$ between DT263 and LGB62, which indicates that the terrain is relatively flat. The velocity becomes larger than $20 \mathrm{~m} \mathrm{a}^{-1}$ until it reaches site LGB66, and increases to $98.2 \mathrm{~m} \mathrm{a}^{-1}$ at site LT980.

\section{Accuracy evaluation of InSAR derived surface velocity}

The accuracy of surface velocity field from InSAR over the Dome A (Rignot and others, 2011) is assessed using the GPS-derived surface velocity (Yang and others, 2014) updated in this study. The InSAR surface velocity field in our area of interest is version 2.0 given by Mouginot and others (2017) and posted on a $450 \mathrm{~m}$ grid. This dataset is an update to a previous version and contains post-2011 SAR data and Landsat-8 satellite imagery, combined using an updated mosaicking method.

The surface ice-velocity along the traverse route is shown in Figure 3a. From Figure 3a, it is clear that GPS results are larger than those of InSAR within the $500 \mathrm{~km}$ from the coast. Between 500 and $1000 \mathrm{~km}$, they are consistent. From 1000 to $1250 \mathrm{~km}$, InSAR results are larger than those of GPS. To show this more clearly, we derived the scale value between InSAR and GPS and shown in Figure 3b. Within the 500 $\mathrm{km}$, the mean scale value is 0.82 and increases to 0.91 between 500 and $1000 \mathrm{~km}$. From 1000 to $1250 \mathrm{~km}$, the mean scale value is 7.71 with the largest 41.72 . Meanwhile, the mean scale over Dome $A$ is 8.77 , which is close to that from 1000 to $1250 \mathrm{~km}$. Hence, when surface velocities are larger than $5.0 \mathrm{~m} \mathrm{a}^{-1}$ (from coast to $1000 \mathrm{~km}$ ), GPS results are larger than InSAR, and InSAR result is only $87 \%$ of that of GPS. When surface velocities are $<5.0 \mathrm{~m} \mathrm{a}^{-1}$, InSAR results are larger than GPS, with the magnitude of InSAR velocities up to 8.24 times of the GPS values.

The GPS velocities are generally larger than those from InSAR, with a mean difference $\sim 1.31 \mathrm{~m} \mathrm{a}^{-1}$ and a Std dev. of $2.55 \mathrm{~m} \mathrm{a}^{-1}$, respectively. The largest difference between GPS and InSAR velocity is at a site $\sim 100 \mathrm{~m} \mathrm{a}^{-1}$ close to coastal regions. Meanwhile, the average InSAR velocity reported error provided Mouginot and others (2017) is $3.52 \mathrm{~m} \mathrm{a}^{-1}$, which is 1.38 times of the Std dev. of the difference, which indicates that the InSAR reported error is different from the actual error. The mean difference, Std dev. of the velocity difference and the InSAR average reported error are $\sim 2.23,2.51$ and $4.27 \mathrm{~m} \mathrm{a}^{-1}$ with velocities larger than $5.0 \mathrm{~m}$ $\mathrm{a}^{-1}$, and they change to $-0.81,0.66$ and $1.78 \mathrm{~m} \mathrm{a}^{-1}$ with velocities $<5.0 \mathrm{~m} \mathrm{a}^{-1}$. 
a
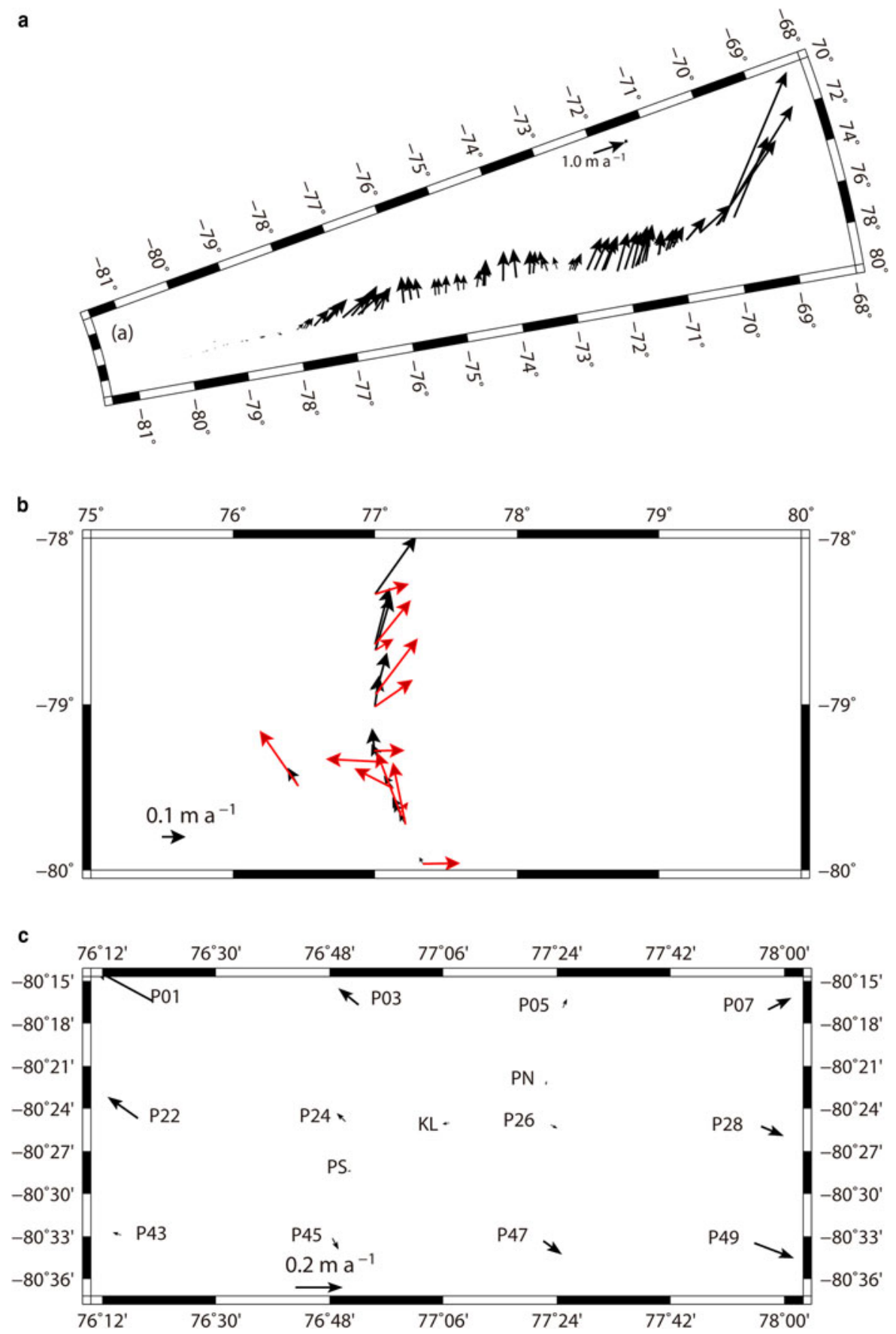

Fig. 2. Horizontal ice surface velocity estimates from (a) GPS along the transect, (b) GPS and InSAR along parts of the transect with magnitude $<5 \mathrm{~m} \mathrm{a}^{-1}$. Red is InSAR, and Black is GPS estimates, respectively, and (c) GPS around Dome A.

The velocity directions estimated from GPS and InSAR are roughly consistent, with the mean and the Std dev. of the directional differences are $4.4^{\circ}$ and $37.7^{\circ}$, respectively. Meanwhile, the average error of velocity direction derived from InSAR is $27.4^{\circ}$, which is 0.74 of the Std dev. of the difference. The mean difference, Std dev. of the velocity direction difference and the InSAR error are $\sim 0.9^{\circ}, 12.9^{\circ}$ and $11.6^{\circ}$ with velocities larger than $5.0 \mathrm{~m} \mathrm{a}^{-1}$, indicating that the velocity directions from InSAR are consistent with GPS. However, they increase to $16.5^{\circ}, 65.0^{\circ}$ and $63.8^{\circ}$ with velocities $<5.0 \mathrm{~m} \mathrm{a}^{-1}$, therefore the accuracy of the InSAR velocity in these regions is limited. As shown in Figure $2 b$, large direction differences in GPS and InSAR exist.

We attribute the discrepancies between InSAR and GPS to errors in InSAR observations (shown in Table 3), or its insensitivity at low ice surface velocity estimates. Our assessment results here suggested that one may want to be cautious about InSAR surface velocity estimates in this East Antarctica study region, when their magnitude is $<5 \mathrm{~m} \mathrm{a}^{-1}$.

\section{CONCLUSION}

Using the repeat GPS measurements after 2005, we updated the new surface velocity estimates along the traverse route from Zhongshan station to and around Dome A. The horizontal ice surface velocities increase from near zero at the summit to near $100 \mathrm{~m} \mathrm{a}^{-1}$ close to the coast. From Dome A, velocity speed increases to 1,10 and $20 \mathrm{~m} \mathrm{a}^{-1}$ at the sites DT416, DT333 and DT263, respectively. 


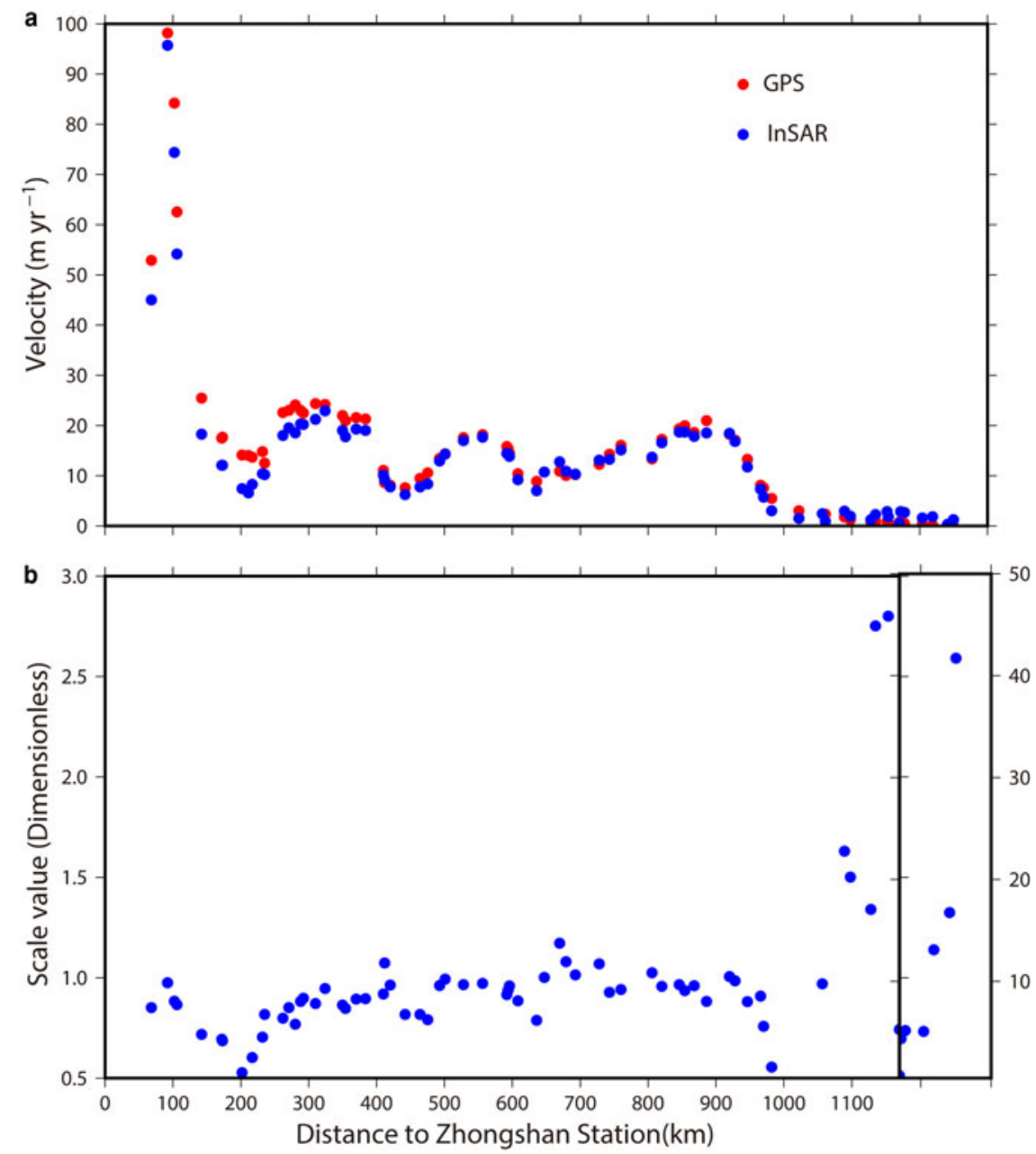

Fig. 3. (a) GPS and InSAR surface velocity along the transect, (b) the factor value derived as the ratio between InSAR surface velocity and corresponding GPS surface velocity.

Table 3. Comparison between GPS velocity and Azimuth (unit: $\mathrm{m} \mathrm{a}^{-1},{ }^{\circ}$, respectively) and InSAR velocity components along the route

\begin{tabular}{|c|c|c|c|c|}
\hline Site & Velo.GPSm a ${ }^{-1}$ & Azim.GPS ${ }^{\circ}$ & Velo.InSARm a ${ }^{-1}$ & Azim.InSAR ${ }^{\circ}$ \\
\hline LGB72 & 52.9 & 306 & $45.0 \pm 6.1$ & $305.9 \pm 3.9$ \\
\hline LT980 & 98.2 & 306 & $95.8 \pm 6.4$ & $305.6 \pm 1.9$ \\
\hline LT975 & $84.2 \pm 0.1$ & $315.2 \pm 0.1$ & $74.4 \pm 5.1$ & $316.9 \pm 2.0$ \\
\hline LGB71 & 62.6 & 318 & $54.2 \pm 7.4$ & $322.4 \pm 3.9$ \\
\hline LGB70 & 25.5 & 331 & $18.3 \pm 6.4$ & $337.4 \pm 10.0$ \\
\hline LT940 & 17.5 & 324 & $12.1 \pm 6.3$ & $357.6 \pm 14.9$ \\
\hline LGB69 & 17.7 & 323 & $12.1 \pm 6.3$ & $357.6 \pm 14.9$ \\
\hline LGB68 & 14.1 & 310 & $7.4 \pm 7.7$ & $294.3 \pm 29.6$ \\
\hline LT921 & $14.1 \pm 0.1$ & $302.6 \pm 0.2$ & $6.6 \pm 5.9$ & $300.0 \pm 25.4$ \\
\hline LT918 & 13.7 & 300 & $8.3 \pm 5.8$ & $285.2 \pm 20.0$ \\
\hline LGB67 & 14.8 & 287 & $10.4 \pm 5.3$ & $271.6 \pm 14.5$ \\
\hline LT909 & $12.5 \pm 0.2$ & $296.7 \pm 0.5$ & $10.2 \pm 5.2$ & $268.7 \pm 14.7$ \\
\hline LGB66 & 22.6 & 292 & $18.1 \pm 4.2$ & $291.5 \pm 6.6$ \\
\hline LT891 & $23 \pm 0.1$ & $296.3 \pm 0.1$ & $19.6 \pm 5.5$ & $294.8 \pm 8.1$ \\
\hline LT887 & $24.1 \pm 0.1$ & $294.5 \pm 0.1$ & $18.6 \pm 4.1$ & $295.8 \pm 6.4$ \\
\hline LT883 & $23 \pm 0.5$ & $304.2 \pm 0.6$ & $20.3 \pm 4.7$ & $295.4 \pm 6.6$ \\
\hline LGB65 & 22.5 & 295 & $20.2 \pm 4.4$ & $298.1 \pm 6.2$ \\
\hline DT008 & $24.4 \pm 0.1$ & $299.9 \pm 0.1$ & $21.2 \pm 5.8$ & $293.1 \pm 7.8$ \\
\hline LGB64 & 24.2 & 297 & $22.9 \pm 6.2$ & $293.6 \pm 7.8$ \\
\hline DT028 & $22.0 \pm 0.2$ & $303 \pm 0.2$ & $19.0 \pm 5.4$ & $301.6 \pm 8.1$ \\
\hline LGB63 & 21 & 304 & $17.8 \pm 5.4$ & $308.8 \pm 8.6$ \\
\hline DT038 & 21.6 & 306 & $19.3 \pm 4.8$ & $309.4 \pm 7.2$ \\
\hline LGB62 & 21.3 & 306 & $19.1 \pm 4.5$ & $300.0 \pm 6.8$ \\
\hline DT058 & $11.1 \pm 0.1$ & $304.3 \pm 0.4$ & $10.2 \pm 4.5$ & $301.1 \pm 12.7$ \\
\hline LGB61 & 8.6 & 310 & $9.2 \pm 5.8$ & $293.1 \pm 18.1$ \\
\hline
\end{tabular}


Table 3. (Cont.)

\begin{tabular}{|c|c|c|c|c|}
\hline Site & Velo.GPSm a ${ }^{-1}$ & Azim.GPS ${ }^{\circ}$ & Velo.InSARm a ${ }^{-1}$ & Azim.InSAR ${ }^{\circ}$ \\
\hline DT063 & $8.1 \pm 0.2$ & $300.3 \pm 1.0$ & $7.8 \pm 4.4$ & $306.4 \pm 16.0$ \\
\hline LGB60 & 7.6 & 265 & $6.2 \pm 3.5$ & $258.0 \pm 16.1$ \\
\hline DT085 & $9.5 \pm 0.1$ & $264.3 \pm 0.2$ & $7.8 \pm 5.7$ & $263.3 \pm 21.0$ \\
\hline LGB59 & 10.6 & 276 & $8.4 \pm 5.5$ & $277.6 \pm 18.7$ \\
\hline DT100 & $13.4 \pm 0.3$ & $286.9 \pm 0.6$ & $12.9 \pm 4.3$ & $286.2 \pm 9.5$ \\
\hline DT104 & $14.4 \pm 0.1$ & $283.9 \pm 0.2$ & $14.3 \pm 5.2$ & $281.9 \pm 10.5$ \\
\hline DT118 & $17.6 \pm 0.4$ & $276.1 \pm 0.6$ & $17.0 \pm 5.0$ & $278.7 \pm 8.4$ \\
\hline DT132 & 18.2 & 283 & $17.7 \pm 4.4$ & $276.3 \pm 7.2$ \\
\hline DT150 & $15.8 \pm 0.1$ & $283.9 \pm 0.2$ & $14.5 \pm 3.5$ & $280.7 \pm 6.9$ \\
\hline DT151 & $15.4 \pm 0.2$ & $284.4 \pm 0.4$ & $14.4 \pm 3.4$ & $281.2 \pm 6.8$ \\
\hline DT152 & $14.4 \pm 0.2$ & $286.3 \pm 0.5$ & $13.9 \pm 3.6$ & $284.1 \pm 7.3$ \\
\hline DT158 & $10.4 \pm 0.1$ & $290.7 \pm 0.3$ & $9.2 \pm 6.9$ & $282.5 \pm 21.4$ \\
\hline DT171 & $8.9 \pm 0.4$ & $282.6 \pm 1.2$ & $7.0 \pm 3.4$ & $278.7 \pm 14.1$ \\
\hline DT177 & $10.7 \pm 0.1$ & $276 \pm 0.3$ & $10.7 \pm 2.4$ & $270.1 \pm 6.5$ \\
\hline DT189 & $10.9 \pm 0.3$ & $283.6 \pm 0.7$ & $12.8 \pm 6.0$ & $293.1 \pm 13.5$ \\
\hline DT193 & $10.1 \pm 0.5$ & $280.1 \pm 1.4$ & $10.9 \pm 4.7$ & $277.1 \pm 12.4$ \\
\hline DT200 & $10.2 \pm 0.5$ & $278.3 \pm 1.4$ & $10.3 \pm 3.3$ & $271.2 \pm 9.2$ \\
\hline DT217 & $12.3 \pm 0.1$ & $272.2 \pm 0.2$ & $13.2 \pm 1.9$ & $267.2 \pm 4.2$ \\
\hline DT224 & $14.3 \pm 0.4$ & $274.3 \pm 0.7$ & $13.2 \pm 2.0$ & $272.3 \pm 4.4$ \\
\hline DT233 & $16.1 \pm 0.2$ & $277.3 \pm 0.3$ & $15.2 \pm 2.4$ & $277.3 \pm 4.6$ \\
\hline DT256 & $13.4 \pm 0.1$ & $297.8 \pm 0.2$ & $13.7 \pm 3.7$ & $296.1 \pm 7.9$ \\
\hline DT263 & $17.3 \pm 0.1$ & $316.5 \pm 0.1$ & $16.6 \pm 4.0$ & $306.9 \pm 7.1$ \\
\hline DT276 & $19.3 \pm 0.2$ & $311.5 \pm 0.2$ & $18.7 \pm 1.9$ & $310.3 \pm 3.0$ \\
\hline DT280 & $19.9 \pm 0.5$ & $330.5 \pm 0.5$ & $18.7 \pm 1.9$ & $315.4 \pm 2.9$ \\
\hline DT287 & $18.6 \pm 0.5$ & $323.5 \pm 0.5$ & $17.9 \pm 3.7$ & $316.1 \pm 6.0$ \\
\hline DT296 & $21.0 \pm 0.5$ & $332.5 \pm 0.5$ & $18.5 \pm 2.5$ & $329.7 \pm 3.9$ \\
\hline DT313 & $18.3 \pm 0.1$ & $325.2 \pm 0.2$ & $18.4 \pm 1.3$ & $323.3 \pm 2.1$ \\
\hline DT317 & $17.1 \pm 0.5$ & $325.7 \pm 0.8$ & $16.9 \pm 1.7$ & $324.1 \pm 2.9$ \\
\hline DT326 & $13.3 \pm 0.2$ & $324.3 \pm 0.5$ & $11.7 \pm 1.8$ & $323.9 \pm 4.3$ \\
\hline DT336 & $8.1 \pm 0.2$ & $317.8 \pm 0.8$ & $7.4 \pm 1.7$ & $313.0 \pm 6.7$ \\
\hline DT338 & $7.6 \pm 0.2$ & $316.4 \pm 0.8$ & $5.8 \pm 1.7$ & $306.3 \pm 8.5$ \\
\hline DT344 & $5.5 \pm 0.1$ & $329.1 \pm 0.5$ & $3.1 \pm 2.9$ & $301.8 \pm 27.0$ \\
\hline DT364 & $3.0 \pm 0.1$ & $35.3 \pm 0.6$ & $1.5 \pm 2.6$ & $73.3 \pm 50.1$ \\
\hline DT381 & $2.5 \pm 0.1$ & $14.3 \pm 0.6$ & $2.4 \pm 1.9$ & $38.8 \pm 22.3$ \\
\hline DT383 & $2.4 \pm 0.2$ & $16.3 \pm 2.4$ & $0.9 \pm 1.8$ & $58.1 \pm 57.6$ \\
\hline DT397 & $1.8 \pm 0.1$ & $15.1 \pm 2.4$ & $2.9 \pm 1.8$ & $37.1 \pm 17.9$ \\
\hline DT401 & $1.3 \pm 0.1$ & $8.0 \pm 2.3$ & $2.0 \pm 2.0$ & $55.4 \pm 29.6$ \\
\hline DT416 & $1.0 \pm 0.1$ & $354.4 \pm 3.0$ & $1.3 \pm 2.2$ & $89.4 \pm 49.2$ \\
\hline DT419 & $0.8 \pm 0.1$ & $336.5 \pm 2.6$ & $2.3 \pm 2.8$ & $272.9 \pm 34.8$ \\
\hline DT428 & $0.9 \pm 0.2$ & $330 \pm 4.8$ & $2.9 \pm 2.2$ & $325.2 \pm 22.4$ \\
\hline DT429 & $0.7 \pm 0.1$ & $323.7 \pm 2.6$ & $1.8 \pm 2.6$ & $297.1 \pm 39.9$ \\
\hline DT437 & $0.7 \pm 0.3$ & $332.7 \pm 11.6$ & $0.5 \pm 1.0$ & $36.1 \pm 52.5$ \\
\hline DT438 & $0.7 \pm 0.2$ & $330.4 \pm 10.8$ & $2.9 \pm 0.8$ & $339.0 \pm 8.1$ \\
\hline DT441 & $0.5 \pm 0.1$ & $329.1 \pm 5.6$ & $2.7 \pm 1.0$ & $348.4 \pm 10.4$ \\
\hline DT454 & $0.3 \pm 0.1$ & $330.5 \pm 14.4$ & $1.6 \pm 2.2$ & $89.1 \pm 39.3$ \\
\hline DT461 & $0.1 \pm 0.1$ & $338.4 \pm 20.1$ & $1.9 \pm 0.7$ & $307.3 \pm 10.4$ \\
\hline $\mathrm{PN}$ & $0.02 \pm 0.01$ & $190.9 \pm 7.6$ & $0.32 \pm 1.92$ & $153.8 \pm 173.3$ \\
\hline $\mathrm{KL}$ & $0.03 \pm 0.01$ & $260.6 \pm 2.0$ & $1.22 \pm 2.21$ & $1.2 \pm 51.8$ \\
\hline P01 & $0.29 \pm 0.02$ & $298.4 \pm 1.6$ & $1.03 \pm 0.74$ & $295.6 \pm 20.7$ \\
\hline P03 & $0.11 \pm 0.01$ & $309.3 \pm 3.1$ & $0.63 \pm 0.73$ & $313.6 \pm 33.4$ \\
\hline P05 & $0.04 \pm 0.01$ & $23.5 \pm 7.9$ & $0.24 \pm 1.00$ & $112.9 \pm 120.2$ \\
\hline P07 & $0.11 \pm 0.02$ & $63.3 \pm 4.6$ & $0.32 \pm 2.52$ & $182.6 \pm 134.0$ \\
\hline P22 & $0.16 \pm 0.01$ & $305.4 \pm 1.1$ & $0.66 \pm 0.88$ & $316.9 \pm 38.6$ \\
\hline P24 & $0.05 \pm 0.01$ & $313.9 \pm 1.7$ & $0.49 \pm 1.71$ & $255.8 \pm 99.8$ \\
\hline P26 & $0.03 \pm 0.01$ & $119.4 \pm 3.7$ & $0.22 \pm 2.62$ & $183.8 \pm 22.2$ \\
\hline P28 & $0.10 \pm 0.01$ & $113.3 \pm 1.4$ & $0.44 \pm 2.11$ & $209.6 \pm 137.6$ \\
\hline P43 & $0.04 \pm 0.01$ & $287.7 \pm 9.5$ & $0.28 \pm 2.12$ & $342.7 \pm 144.5$ \\
\hline P45 & $0.05 \pm 0.01$ & $152 \pm 6.3$ & $1.10 \pm 1.78$ & $211.7 \pm 46.4$ \\
\hline P47 & $0.10 \pm 0.01$ & $126.2 \pm 4.1$ & $0.61 \pm 2.44$ & $137.7 \pm 115.4$ \\
\hline P49 & $0.18 \pm 0.01$ & $110.9 \pm 1.9$ & $0.80 \pm 1.75$ & $187.9 \pm 63.1$ \\
\hline PS & $0.02 \pm 0.01$ & $77.7 \pm 8.6$ & $0.51 \pm 1.55$ & $26.8 \pm 144.3$ \\
\hline
\end{tabular}

The comparison between GPS and InSAR indicates that the InSAR velocity reported error is overestimated, with actual error $2.55 \mathrm{~m} \mathrm{a}^{-1}$ and reported error $3.52 \mathrm{~m} \mathrm{a}^{-1}$, respectively. Within the $1000 \mathrm{~km}$ from the coast, GPS is larger than InSAR, and becomes less than that of InSAR after $1000 \mathrm{~km}$. To be consistent with estimates of ice velocity obtained with GPS measurements, a scale value can be applied to InSAR results. When the surface velocity is larger than $5 \mathrm{~m} \mathrm{a}^{-1}$, the scale value is $\sim 1.15$, and it decreases to 0.12 with the surface velocity $<5 \mathrm{~m} \mathrm{a}^{-1}$. 
The GPS-derived surface velocity field over a decade, 2005-16, provides a critical glaciological measurement and quality control for InSAR results in Antarctica. We find that the InSAR surface velocity estimates with magnitude $<5 \mathrm{~m} \mathrm{a}^{-1}$, may be in error due to the insensitivity of InSAR to low-velocity estimates and/or InSAR data processing errors. In order to capture correct signatures of ice dynamics and mass balance in an area such as Dome A, it is important to combine various data types such as surface velocity, surface topography, ice thickness and snow accumulation, towards studies addressing Dome A long-term stability in a warming climate.

\section{ACKNOWLEDGEMENTS}

We thank the Chinese Arctic and Antarctic Administration, State Oceanic Administration, for sponsoring the field surveying and research works. This study is funded by NSFC (41531069, 41476163, 41476162, 41106163), MOST (2013CBA01804) and SOA (CHINARE 2016, 2017). We thank the anonymous reviewers for helpful comments.

\section{REFERENCES}

Alley RB, Clark PU, Huybrechts P and Joughin I (2005) Ice sheet and sea-level changes. Science, 310(5747), 456-460

Bell R and 11 others (2011) Widespread persistent thickening of the East Antarctic ice sheet by freezing from the base. Science, 331, 1592-1595

Capra A and 5 others (2000) Surface topography of Dome Concordia (Antarctica) from kinematic interferential GPS and bedrock topography. Ann. Glaciol., 30, 42-46

Cheng X, Gong P, Zhang Y, Sun Z and Wei F (2009) Surface topography of Dome A, Antarctica, from differential GPS measurements. J. Glaciol., 55, 185-187

Cui $X$ and 7 others (2010) Ice radar investigation at Dome A, East Antarctica: ice thickness and subglacial topography. Chinese Sci. Bull., 55(4), 425-431

Ding $M$ and 6 others (2011) Spatial variability of surface mass balance along a traverse route from Zhongshan station to Dome A, Antarctica. J. Glaciol., 57(204), 658-666 (doi: 10.3189/002214311797409820)

Ding $M$ and 8 others (2016) Re-assessment of recent (2008-2013) surface mass balance over Dome Argus, Antarctica. Polar Res., 35, 26133

Gudmundsson GH (2006) Fortnightly variations in the flow velocity of Rutford Ice Stream, West Antarctica. Nature, 444(7122), 1063-1064

Hou S, Li Y, Xiao C and Ren J (2007) Recent accumulation rate at Dome A, Antarctica. Chinese Sci. Bull., 52(3), 428-431
Jiang W, E DC, Zhan B and Liu Y (2009) New model of Antarctic plate motion and its analysis. Chinese J. Geophys., 52 (1), 23-32

Kiernan R (2001) Ice sheet surface velocities along the Lambert Glacier basin traverse route. Antarct. CRC Res. Rep. 23

King RW (2002) Documentation for the GAMIT GPS Analysis Software, Release 10.05. Massachusetts Institute of Technology, Cambridge, MA

King MA, Coleman R, Morgan PJ and Hurd RS (2007) Velocity change of the Amery Ice Shelf, East Antarctica, during the period 1968-1999. J. Geophys. Res., 112(F1), F01013 (doi: 10.1029/2006JF000609)

Ma Y, Bian L, Xiao C, Allison I and Zhou X (2010) Near surface climate of the traverse route from Zhongshan Station to Dome A, East Antarctica. Antarct. Sci., 22(4), 443-459

Meier MF (1993) Ice, climate, and sea level: do we know what is happening? In Peltier WR ed. Ice in the Climate System. Springer-Verlag, Berlin, etc., 141-160 (NATO ASI Series I: Global Environmental Change 12.)

Mouginot J, Rignot E, Scheuchl B and Millan R (2017) Comprehensive annual ice sheet velocity mapping using Landsat-8, Sentinel-1, and RADARSAT-2 data. Remote Sens., 9 (4), Art. \#364 (doi: 10.3390/rs9040364)

Paterson WSB (1994) The Physics of Glaciers, 3rd edn. Elsevier, Oxford, etc.

Qin D and 6 others (2004) Snow surface height variations on the Antarctic ice sheet in Princess Elizabeth Land, Antarctica: 1 year of data from an automatic weather station. Ann. Glaciol., 39, 181-187

Ren J, Sun J and Qin D (2004) Preliminary results of ionic concentrations in snow pits along the Zhongshan-Dome A traverse route, Antarctica. Ann. Glaciol., 39, 155-160

Rignot E, Mouginot J and Scheuchl B (2011) Ice flow of the Antarctic Ice sheet. Science, 333, 1427-1430

Sun B and 8 others (2009) The Gamburtsev mountains and the origin and early evolution of the Antarctic ice sheet. Nature, 459, 690-693

Tabacco IE, Passerini A, Corbelli F and Gorman MR (1998) Determination of the surface and bed topography at Dome C, East Antarctica. J. Glaciol., 44(146), 185-191

Vittuari L and 6 others (2004) Space geodesy as a tool for measuring ice surface velocity in the Dome $\mathrm{C}$ region and along the ITASE traverse. Ann. Glaciol., 39, 402-408

Xiao C and 9 others (2008) Surface characteristics at Dome A, Antarctica: first measurements and a guide to future ice-coring sites. Ann. Glaciol., 48, 82-87

Yang Y and 8 others (2014) GPS-derived velocity and strain fields around Dome Argus, Antarctica. J. Glaciol., 60(222), 735-742

Zhang S, E DC, Wang Z, Zhou C and Shen Q (2007) Surface topography around the summit of Dome A, Antarctica, from real-time kinematic GPS. J. Glaciol., 53(180), 159-160

Zhang S and 5 others (2008) Ice velocity from static GPS observations along the transect from Zhongshan station to Dome A, East Antarctica. Ann. Glaciol., 48, 113-118 